\title{
ステンレス基板上に作製した $\mathrm{Ti}$ 系薄膜の 高真空中に和ける摩擦・摩耗特性*
}

\author{
佐々木道子*1 - 中村 勲*2 - 鷹野 一朗*2 - 沢田 芳夫*2 \\ （受理2000年11月 27 日，掲載決定2001年 2 月 3 日）
}
Tribological Properties of Ti-Based Thin Films Prepared on Stainless Steel in a High Vacuum Michiko SASAKI ${ }^{* 1}$, Isao NAKAMURA ${ }^{* 2}$,
Ichiro TAKANO ${ }^{* 2}$ and Yoshio SAWADA*2

$*_{1}$ (Graduate Schol in Electrical Engineering and Electronics, Kogakuin University, Nakano 2665-1 Hachioji, 192-0015 Tokyo)

*2(Department of Electrical Engineering, Kogakuin University, Nakano 2665-1 Hachioji, 192-0015 Tokyo)

(Received November 27, 2000, Accepted February 3, 2001)

Tribological properties of $\mathrm{Ti}, \mathrm{TiN}$ and $\mathrm{TiO}_{2}$ films based on $\mathrm{Ti}$ element were investigated in a high vacuum simulating a space environment. Stainless steel (304SS) polished to a mirror surface was used as sample substrates. $\mathrm{Ti}_{\mathrm{i}} \mathrm{TiO}_{2}$, and TiN with $0.2 \mu \mathrm{m}$ in film thickness, were prepared on the substrates by vacuum evaporation, ion beam assisted evaporation, and dynamic ion mixing, respectively. The chemical state and atomic composition of the film were analyzed by $\mathrm{X}$ ray photoelectron spectroscopy (XPS), and the microstructure was measured by X-ray diffraction (XRD). The tribological examination was carried out using a high vacuum equipment $\left(3 \times 10^{-5} \mathrm{~Pa}\right)$ with a wear tester of Pin-On-Disk type. The wear surface was observed with an optical microscope and a scanning laser microscope.

The friction coefficients of stainless steel, Ti, TiN in the atmosphere showed a lower value than that in the high vacuum, because an oxygen or moisture in the air has a role of lubrication. Therefore, in the case of oxide films such as $\mathrm{TiO}_{2}$, it is considered that the friction coefficient in the high vacuum showed the same value in the atmosphere.

\section{1. はじめに}

近年, 科学技術の発達とともに宇宙工学も進歩してき た. 宇宙環境は地球環境と比較した場合, 圧力, 温度, 湿度，重力，放射線などの面で大きな違いがある．この ような異なる環境下で摺動部品等を駆動させた場合, 摩 擦係数が地球環境下と比べると大きく増加するため, 䛊 動作や動作不能状態を起こしたり，長期的には寿命が短

\footnotetext{
* 平成12年10月27日 第41回真空に関する連合会で発表

*1 工学院大学大学院電気 - 電子工学専攻（空192-0015 東京都八王子市 中野町2665-1)

*2 工学院大学電気工学科（广192-0015 東京都八王子市中野町 2665-1)
}

くなる等の問題がある.したがって，摩擦をどれだけ低 減させられるかが宇宙施設（人工衛星など）の安全性, 信頼性を向上させる点で重要となる．現状では， $\mathrm{MoS}_{2}$ が宇宙環境下での最適な固体潤滑材として考えられてい るが ${ }^{1,2)}$, 成膜技術の進歩も取り入れ，さらなる材料開 発を行ら必要がある.

本研究では基礎的データ収集を目的として, Ti, TiN および $\mathrm{TiO}_{2}$ の $\mathrm{Ti}$ 系薄膜を作製し ${ }^{3,4)}$ ，大気中 $\left(1 \times 10^{5}\right.$ $\mathrm{Pa})$ と高真空中 $\left(<4 \times 10^{-5} \mathrm{~Pa}\right)$ に扣ける異なる環境下 の摩擦・摩耗特性の違いについて評価を行った。 


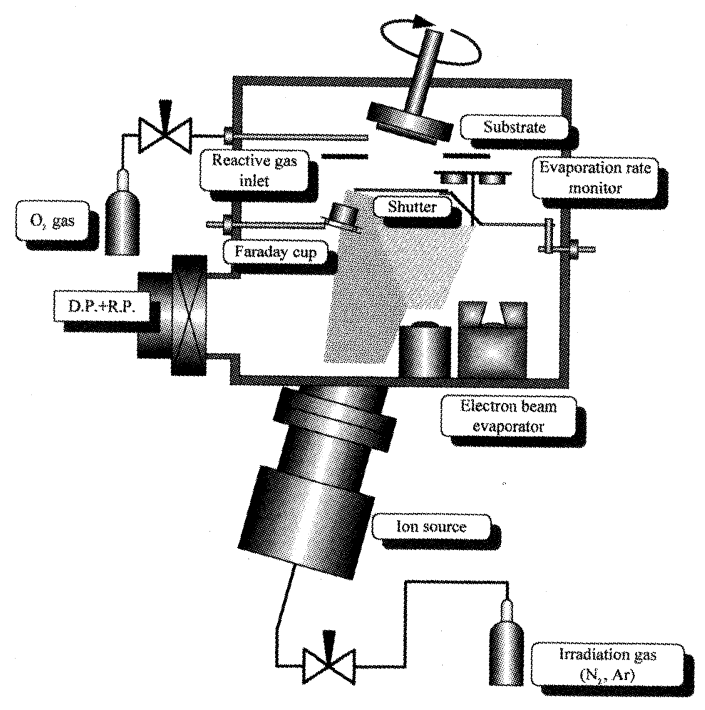

Fig. 1 Schematic diagram of the ion beam mixing system.

\section{2. 実験方法}

\section{1 成膜方法}

成膜には，Fig. 1 に示したイオンビームミキシング装 置（HIIB-200-B (株日立製作所）を用いた。試料基板と して，鏡面研磨されたステンレス鋼（304SS）を用い た.アセトン中で 5 分間超音波洗浄を行った後, サンプ ルホルダーに固定し, チャンバー内を $6.0 \times 10^{-4} \mathrm{~Pa}$ 以下 まで排気した。成膜の前処理として, $\mathrm{Ar}^{+}$イオン照射 による試料表面のクリーニングを10分間行った。 Ti膜 は蒸着法, TiN 膜はダイナミックイオンミキシング法5), そして $\mathrm{TiO}_{2}$ 膜には反応性イオンビームアシスト蒸着 法6)用いて，それぞれ成膜を行った。膜厚は，全て $0.2 \mu \mathrm{m}$ とした。

\section{2 評価方法}

化学結合状態および組成を X 線光電子分光法 (XPS : ESCA-K1S(株)島津製作所)，結晶構造をX線回折法 (XRD: High quality XG M18XCE-MAC Science. Co., Ltd）により分析した.

摩擦・摩耗試験には，Fig. 2 に示したPin-On-Disk 型 高真空材料試験装置（ワールドェンジニアリング(侏) を 用いた．高真空中での摩擦試験では，ロータリーポンプ （R.P.）とターボ分子ポンプ（TMP）を組み合わせた排 気系を用い, チャンバー内を所定の到達圧力まで排気し た。この摩擦試験条件は, 大気中 $\left(1 \times 10^{5} \mathrm{~Pa}\right)$ と高真 空中 $\left(<4 \times 10^{-5} \mathrm{~Pa}\right)$ の 2 種類の雾囲気に执いて, 相手

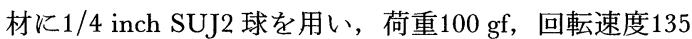

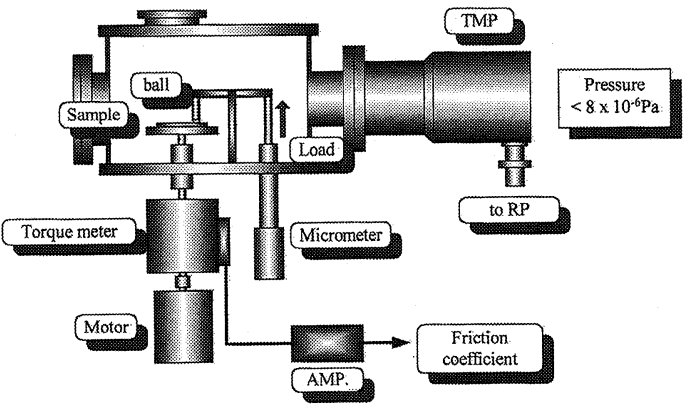

Fig. 2 Schematic diagram of the high vacuum equipment with a wear resistance tester.

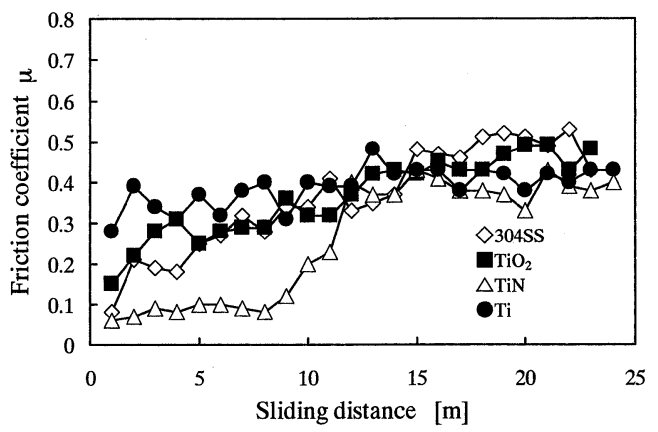

Fig. 3 Friction coefficient of $304 \mathrm{SS}, \mathrm{Ti}, \mathrm{TiN}$ and $\mathrm{TiO}_{2}$ films in the atmosphere $\left(1 \times 10^{5} \mathrm{~Pa}\right)$.

$\mathrm{rpm}$, 摩擦距離を $24 \mathrm{~m}$ とした.

摩擦試験後の摩耗面と相手材を光学顕微鏡（MATSUZAWA SEIKI. Co., Ltd) 括よび走査型レーザー影微 鏡（1LM21レーザーテック(侏）で観察した。また， XPSにより摩耗面の元素分析も併せて行った。

\section{3. 実験結果および考察}

大気中での $304 \mathrm{SS}, \mathrm{Ti}$ 膜, $\mathrm{TiO}_{2}$ 膜拉よび $\mathrm{TiN}$ 膜の摩 擦係数の変化を Fig. 3 に示す. $304 \mathrm{SS}$ と $\mathrm{TiO}_{2}$ 膜の摩擦 係数変化は同様な挙動を示し, 摩擦係数が $0.2(1 \mathrm{~m})$ か ら0.5 $(24 \mathrm{~m})$ まで徐々に高くなった. Ti 膜の場合は, 摩 擦係数 0.35 から始まり, 摩擦距離 $9 \mathrm{~m}$ 以降から摩擦係数 が徐々に高くなり，304SS および $\mathrm{TiO}_{2}$ 膜と同様な值と なった. 一方, TiN 膜は $10 \mathrm{~m}$ まで摩擦係数 0.1 を示し, 他の膜よりも低い值を示した，その後の $24 \mathrm{~m}$ までの摩

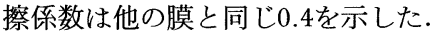

Fig. 4 には, 高真空中に括ける304SS, $\mathrm{Ti}$ 膜, $\mathrm{TiO}_{2}$ 膜 扣よび TiN 膜の摩擦係数変化を示す. TiN 膜の場合, $10 \mathrm{~m}$ までの摩擦係数は大気中よりも高い 0.3 を示した. その後も摩擦係数は高くならず, $24 \mathrm{~m}$ まで摩擦係数 0.3 


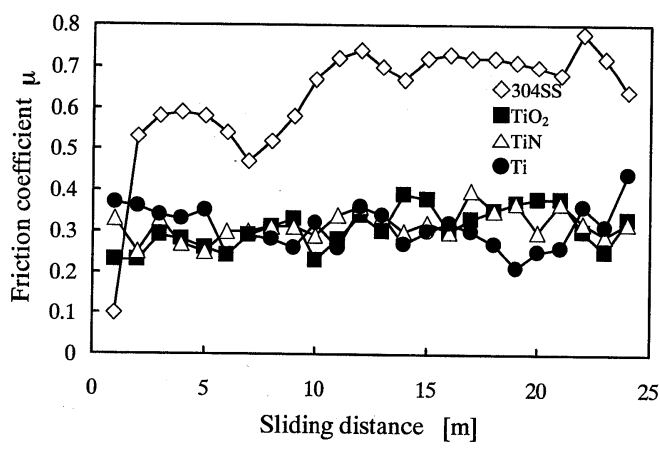

Fig. 4 Friction coefficient of 304SS, Ti, TiN and $\mathrm{TiO}_{2}$ films in the high vacuum $\left(3 \times 10^{-5} \mathrm{~Pa}\right)$.

を保持した。ささらに, $\mathrm{Ti}$ 特よび $\mathrm{TiO}_{2}$ 膜も $\mathrm{TiN}$ 膜と同 様の挙動を示し, $24 \mathrm{~m}$ まで摩擦係数 0.3 を示し, 膜質に よる違いは見られなかった。
大気中と高真空中の摩擦係数変化を比べると，304SS では, 高真空中より大気中での摩擦係数が全体的に 0.3 ほど低い值であった。これは，大気中に存在する $\mathrm{O}_{2}$ 及 び $\mathrm{H}_{2} \mathrm{O}$ 等の影響により摩擦面で酸化が生じ，そこで生 成された酸化物が润滑剂の役割を果たしたためと考兄ら れる. 一方, $\mathrm{O}_{2}$ 及び $\mathrm{H}_{2} \mathrm{O}$ 等が少ない高真空中では， 304SS 表面に酸化が生じにくいため, 摩擦係数は大気中 よりも高い值を示したと考光られる．Ti膜をコーティ ングした試料の場合, $9 \mathrm{~m}$ までの摩擦係数は, 大気中と 高真空中で共に同じ 0.3 をした。 これは，Ti膜コーテ ィング後の表面に酸化皮膜が形成されて $\mathrm{TiO}_{2}$ 膜と同じ 摩擦係数を示したと考兄られる。しかし，大気中では 9 $\mathrm{m}$ 以降の摩擦係数が $0.4(24 \mathrm{~m})$ まで徐々に变化したもの の, 注定の摩摖係数を保持した. 一方, 高真空中で は304SS 上りも Ti 膜の方が低い摩擦係数を示し, $19 \mathrm{~m}$ まで摩擦係数 0.3 保持した．その後は徐々汇高くなり，

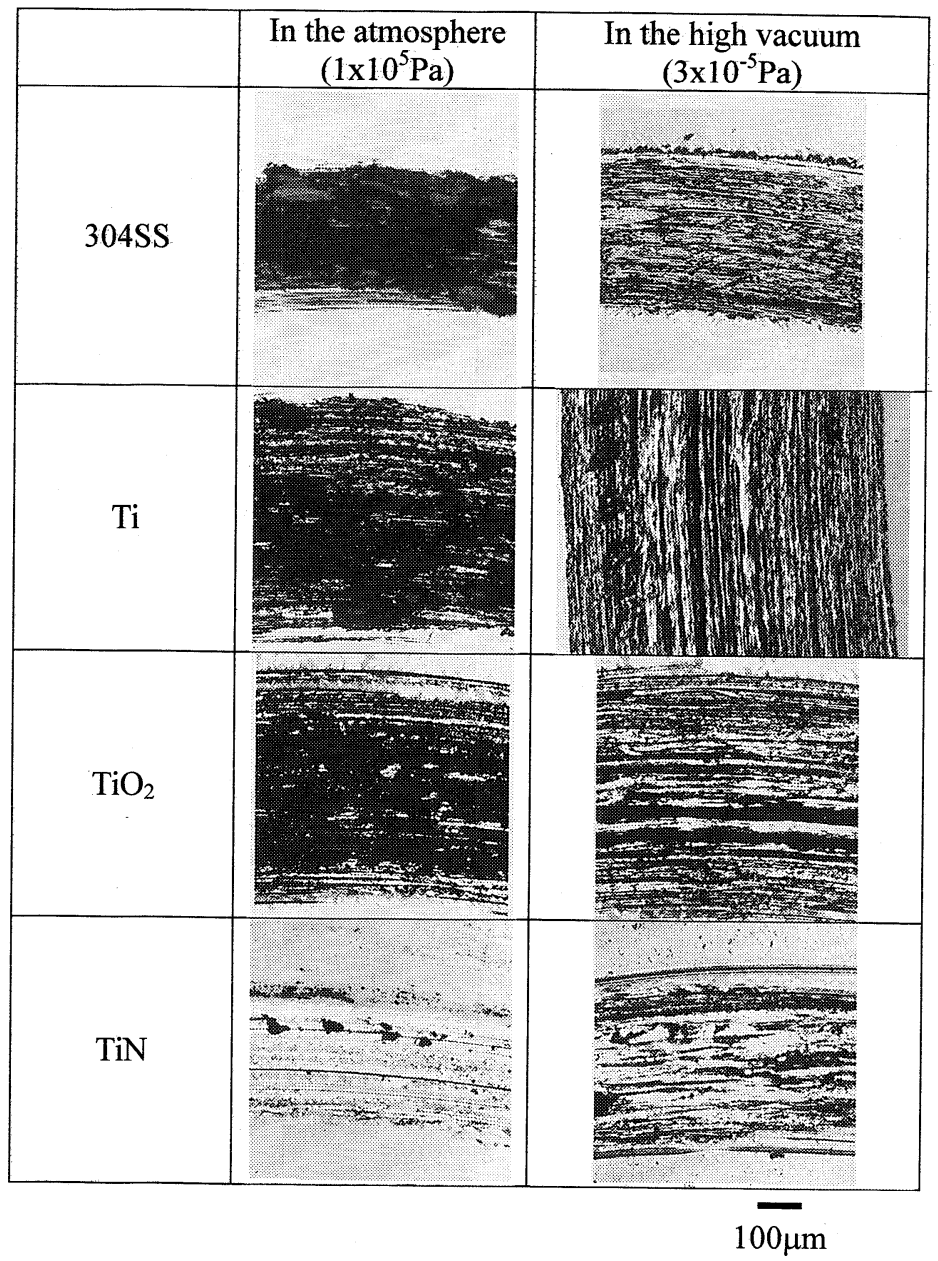

Fig. 5 Wear surface photographs of $304 \mathrm{SS}, \mathrm{Ti}$, TiN and $\mathrm{TiO}_{2}$ films observed by the scanning laser microscope. 


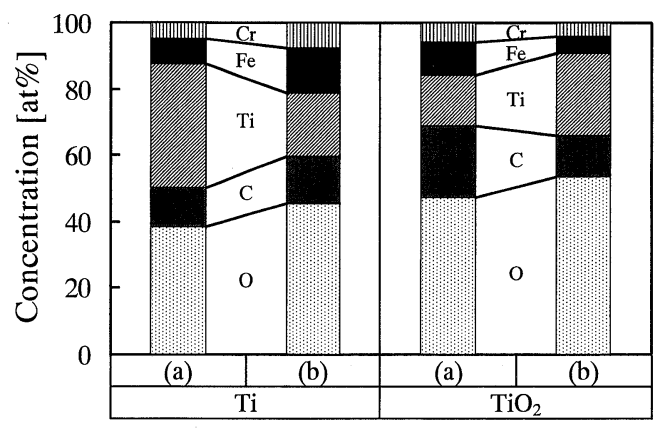

(a) In the atmosphere $\left(1 \times 10^{5} \mathrm{~Pa}\right)$

(b) In the high vacuum $\left(3 \times 10^{-5} \mathrm{~Pa}\right)$

Fig. 6 Atomic concentration of the wear surface of $\mathrm{Ti}$ and $\mathrm{TiO}_{2}$ films measured by XPS.

$22 \mathrm{~m}$ 付近で大気中よりも高い摩擦係数を示した. TiN 膜の場合, $10 \mathrm{~m}$ までの摩擦係数は大気中よりも高真空 中の方が高くなったものの, 高真空中では一定の摩擦係 数 0.3 を長い距離で保持した. 大気中では摩擦距離 $10 \mathrm{~m}$ で膜が剥離し，304SS と同椂になるが，高真空中では酸 化物が生じないため摩擦係数は高くなるものの膜剥離は 生じず一定の摩擦係数を示した.ところが $\mathrm{TiO}_{2}$ 膜の場 合, 膜自体が酸化物のため, 大気中・真空中ともに $\mathrm{O}_{2}$ 及び $\mathrm{H}_{2} \mathrm{O}$ 等による酸化の影響を受けず, 大気中と高真 空中の摩擦係数に大きな違いが見られなかった.

摩擦・摩耗試験後の表面を走査型レーザー顕微鏡で観 察した結果を Fig. 5 亿示す。大気中の試料では, 全て の膜の摩耗面上に酸化物と考兄られる黒い凝着物が観察 された. 一方, 高真空中の場合, 摩耗面上に凝着物は見 られず，摩耗幅は相対的に広くなった。

レーザー顕微鏡による観察結果をもとに, 膜が摩耗面 に残っていると考兄られる $\mathrm{Ti}$ 膜と $\mathrm{TiO}_{2}$ 膜について摩 耗面のXPS 組成分析を行った. Fig. 6 亿示すように， $\mathrm{Ti}$ 膜でコーティングした試料を真空中で摩擦・摩耗試 験した場合には, 大気中に比べて, 摩耗面に残っている
Tiが少なくなっていた．これに対して， $\mathrm{TiO}_{2}$ 膜でュー ティングした試料の摩耗面に残っている Tiは, 高真空 中の方が多かった. 一方, 基材の露出を示す Fekつい て比較すると, $\mathrm{Ti}$ 膜と $\mathrm{TiO}_{2}$ 膜とで前述した $\mathrm{Ti}$ とは逆 の傾向が見られた。これらのことより, 高真空中におけ る摩擦摩耗に関しては, $\mathrm{TiO}_{2}$ 膜の方が優れた特性を示 すと結論できる。

\section{4. まとめ}

酸化の影響を大きく受ける304SS は, 大気中では潤滑 剂の役割を持つ酸化物が生じるため, 高真空中よりも低 い摩擦係数を示した. 一方, Ti 系膜をコーティングし た試料は, $\mathrm{O}_{2}$ 及び $\mathrm{H}_{2} \mathrm{O}$ 等が存在しない高真空中では摩 擦摩耗時に酸化の影響を受けず，各試料とも大気中より も一定の摩擦係数が得られた. このことは, 大気中と高 真空中で $\mathrm{TiO}_{2}$ 膜の摩擦係数に大きな差が見られないこ とからもわかる。また，304SS に Ti 系膜をコーティン グすることで, 高真空中での摩擦係数を低減できること が明らかになった。

本研究は, 文部省ハイテクリサーチセンター整備事業 の一環として行われた.

\section{〔文献〕}

1) M. Suzuki and M. Nishimura: TECHNICAL REPORT OF NATIONAL AEROSPACE LABORAATORY, TR-1389 (1999) p. 2 [in Japanese].

2）加藤康司, 金亭資, 足立幸志, 古山秀之：機論 $\mathrm{C}$, 62-600 (1996) 3237.

3）池田佳直, 斎藤一也, 塚原園子, 西浦正満, 佐藤 勝，大石政治，佐久間泰 : 真空, 38 (1995) 826.

4）笠原 章, 土佐正弘, 吉原一紘 : 真空, 42 (1999) 447.

5) I. Nakamura, M. Kamiya, I. Takano and Y. Sawada: Jpn. J. Appl. Phys., 36 (1997) 2308.

6) 笹瀬雅人, 鷹野一朗, 磯部昭二, 横山修一: 電学論 A, 116 (1996) 804. 